JULIA PRADO MASCARENHAS

\title{
A RECLAMAÇÃO COMO MEIO DE CONTROLE DA APLICAÇÃO DE PRECEDENTES
}

Dissertação de mestrado

Orientador: Prof. Titular Cândido Rangel Dinamarco

UNIVERSIDADE DE SÃO PAULO

FACULDADE DE DIREITO

SÃO PAULO, SP

2018 



\section{A RECLAMAÇÃO COMO MEIO DE CONTROLE DA APLICAÇÃO DE PRECEDENTES}

Dissertação apresentada à banca examinadora do programa de pós-graduação da Faculdade de Direito da Universidade de São Paulo, sob orientação do Prof. Titular Cândido Rangel Dinamarco, como requisito para obtenção do título de mestre.

UNIVERSIDADE DE SÃO PAULO

FACULDADE DE DIREITO

SÃO PAULO, SP

2018 
Catalogação da Publicação

Serviço de Biblioteca e Documentação

Faculdade de Direito da Universidade de São Paulo

Mascarenhas, Julia Prado

A reclamação como meio de controle da aplicação de precedentes / Julia Prado Mascarenhas ; orientador Cândido Rangel Dinamarco -São Paulo, 2018.

146

Dissertação (Mestrado - Programa de Pós-Graduação em Direito Processual) - Faculdade de Direito, Universidade de São Paulo, 2018.

1. Processo civil. 2. Reclamação. 3. Precedentes. 4. Recurso. I. Dinamarco, Cândido Rangel, orient. II. Título. 
MASCARENHAS, Julia Prado

A reclamação como meio de controle da aplicação de precedentes

Dissertação apresentada à Faculdade de Direito da Universidade de São Paulo sob orientação do Prof. Titular Cândido Rangel Dinamarco como requisito para obtenção do título de mestre.

Resultado:

Data:

Orientador

Prof. Titular Cândido Rangel Dinamarco

Prof. Dr. Instituição:

Julgamento: Assinatura:

Prof. Dr. Instituição:

Julgamento: Assinatura:

Prof. Dr Instituição:

Julgamento: Assinatura: 



\section{RESUMO}

Julia Prado Mascarenhas. A reclamação como meio de controle da aplicação de precedentes. 146 páginas. Mestrado - Faculdade de Direito, Universidade de São Paulo, São Paulo, 2018.

O objetivo deste trabalho é analisar a reclamação como meio de controle da aplicação dos precedentes. Pretende-se identificar em que medida a reclamação é instrumento necessário para assegurar a observância dos precedentes vinculantes instituídos pelo Código de Processo Civil de 2015; se o controle de sua aplicação por meio da reclamação seria adequado; e, por fim, quais as principais consequências da ampliação de suas hipóteses de cabimento. O estudo inicia-se com a análise da origem e evolução do instituto, passando pelas suas hipóteses de cabimento previstas pela Constituição Federal de 1988 e aquelas acrescidas pelo Código de Processo Civil de 2015. Em seguida, faz-se uma análise do sistema brasileiro de precedentes, de modo a traçar suas principais características. A parte final do trabalho se dedica à forma como se dá, por meio da reclamação, a impugnação de uma decisão judicial que aplica ou deixa de aplicar um precedente, e quais as principais consequências do desempenho dessa nova função da reclamação. Por fim, resumem-se as principais conclusões obtidas ao longo da dissertação.

Palavras-chave: processo civil; reclamação; precedentes; recurso. 



\begin{abstract}
Julia Prado Mascarenhas. The reclamação as means of control of the application of precedents. 146 pages. Master's degree - Faculty of Law, University of São Paulo, São Paulo, 2018.

The aim of this work is to analyze the reclamação as means of control of the application of precedents. It intends to identify to what extent the reclamação is a necessary instrument to ensure the observance of the binding precedentes instituted by the Brazilian Code of Civil Procedure of 2015; to verify if the control of its application by means of the reclamação is appropriate; and, finally, to know the main consequences of the expantion of its admissibility. The study starts by analyzing the origin and evolution of the institute, with the examination of its admissibility as provided in the Brazilian Federal Constitution of 1988 and in the Brazilian Code of Civil Procedure de 2015. Next, there's an analysis of the Brazilian system of precedents with the purpose of identifying its main features. The final part of the work examinates the objection, by means of the reclamação, of a decision that observes or fails to observe a precedent and the main consequences of this new role of the reclamação. Finally, there's a summary of the main conclusions obtained throughout the dissertation.
\end{abstract}

Keywords: civil procedure; reclamação; precedents, appeal. 



\section{SUMÁRIO}

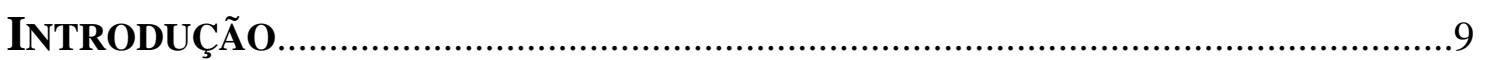

I. ORIGEM E EVOLUÇão DA RECLAMAÇão.......................................................11

I.1. SURGIMENTO JURISPRUDENCIAL E INSERÇÃO NO REGIMENTO INTERNO DO SUPREMO

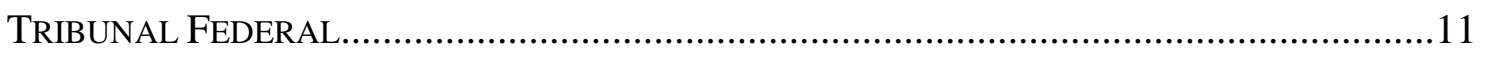

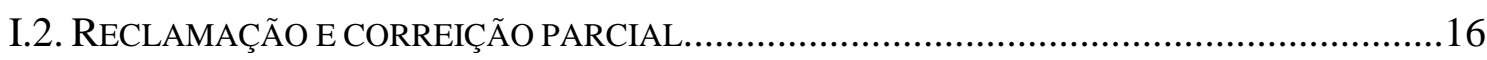

I.3. CONSTITUCIONALIZAÇÃO, LEGISLAÇÃO INFRACONSTITUCIONAL E EXPANSÃO..............20

I.4. A ReClaMaÇão No Código de Processo Civil De 2015..........................................25

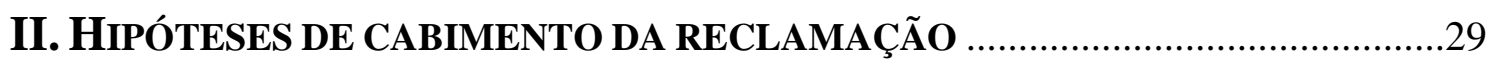

II.1. GARANTIA DA AUTORIDADE DAS DECISÕES DOS TRIBUNAIS........................................29

II.2. RECLAMAÇÃO NO CONTROLE CONCENTRADO DE CONSTITUCIONALIDADE.....................34

II.3. INOBSERVÂNCIA DE SÚMULA VINCULANTE..............................................................40

II.4. RECLAMAÇÃO PARA DIRIMIR DIVERGÊNCIA ENTRE ACÓRDÃO DE TURMA RECURSAL E A JURISPRUDÊNCIA DO SUPERIOR TRIBUNAL DE JUSTIÇA ...................................................45

II.5. CASOS REPETITIVOS, REPERCUSSÃo GERAL E ASSUnção DE

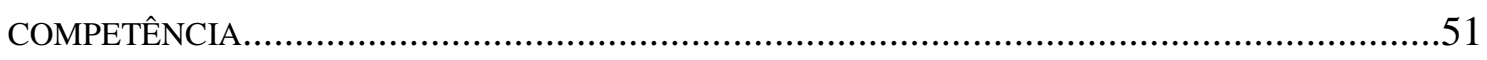

III. BREVE ANÁlise do SISTEMA de PRECEDENTES INSTITUído PELO

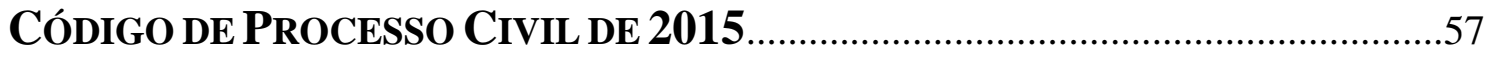

III.1. A EVOLUÇÃO DO PAPEL DAS DECISÕES JUDICIAIS NO ORDENAMENTO BRASILEIRO.....57

III.2. OS PRECEDENTES NO CóDIGO DE PROCESSO CIVIL DE 2015 .........................................64

III.2.1. Precedente, jurisprudência e súmula............................................................64

III.2.2. Principais características do sistema de precedentes do CPC-15...............66

III.3. O ART. 927 DO Código De PROCESSO CIVIL E OS PRECEDENTES VINCULANTES..........71

III.3.1. Eficácia vinculante e reclamação................................................................73

III. 4. A APLICAÇÃO DOS PRECEDENTES E A RELEVÂNCIA DA MOTIVAÇÃO.............................77

III.4.1. A decisão judicial que contraria precedente vinculante.............................84 

IV. A reclamaÇão COMO Meio de CONTRole da aplicaÇão de PRECEDENTES

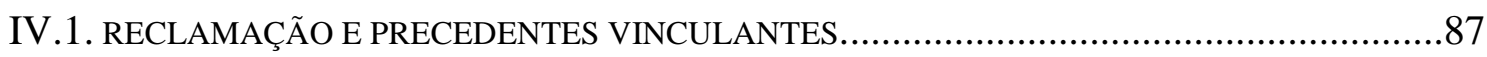

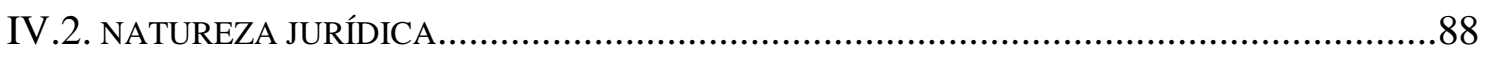

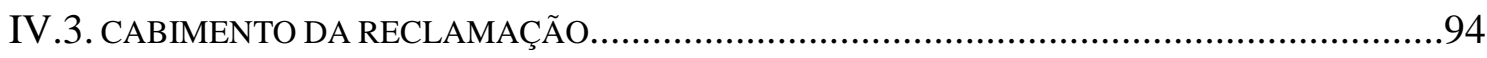

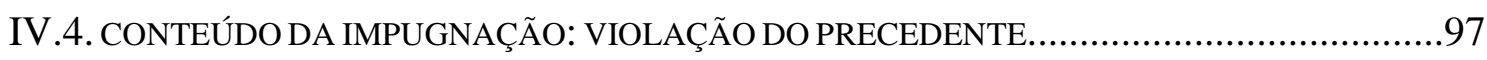

IV.4.1. Necessidade de violação expressa....................................................99

IV.5. PROCEDÊNCIA DA RECLAMAÇÃO: EFEITO RESCINDENTE .....................................104

IV.6. RECLAMAÇÃO E RECURSO - AUTONOMIA E CONCORRÊNCIA..................................113

IV.7 A RECLAMAÇÃO COMO MEIO INADEQUADO AO CONTROLE DA APLICAÇÃO DE

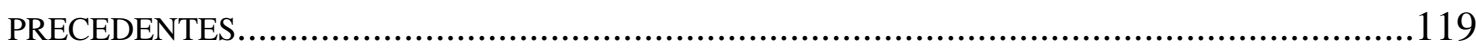

IV.7.1. Ampliação das hipóteses de cabimento e generalização do acesso aos tribunais de superposiçãa ................................................................124

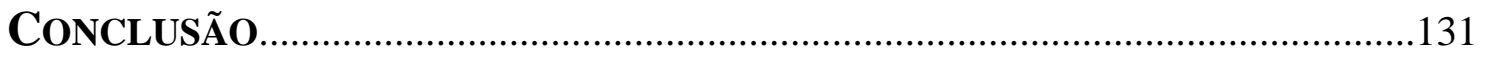

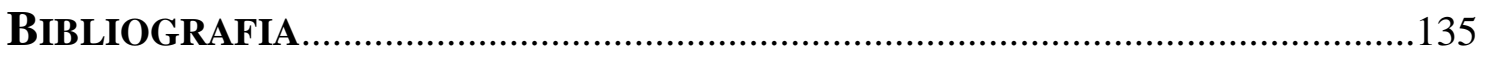





\section{INTRODUÇÃO}

A reclamação constitucional é um instituto que já há algum tempo vem ganhando destaque no cenário processual. O interesse em seu estudo foi renovado pelo Código de Processo Civil de 2015, que ampliou suas hipóteses de cabimento e lhe conferiu o papel de instrumento de controle da aplicação de determinados precedentes obrigatórios.

O objetivo deste estudo é analisar a nova função atribuída à reclamação, especificamente o modo como será desempenhada, as consequências da relação entre a reclamação e precedentes e de que maneira isso impacta na compreensão desse instituto. Por meio dessa análise pretende-se identificar em que medida a reclamação é instrumento necessário para assegurar a observância dos precedentes vinculantes, se o controle de sua aplicação por meio da reclamação seria adequado e, por fim, quais as principais consequências da ampliação de suas hipóteses de cabimento.

No primeiro capítulo serão abordadas a origem e a evolução da reclamação, buscando identificar o contexto de sua criação e os principais marcos de sua trajetória, que ainda hoje são essenciais para compreender alguns dos contornos do instituto. É importante observar que a reclamação em sua origem não era associada à observância de precedentes: ela teve origem na jurisprudência do Supremo Tribunal Federal, como mecanismo voltado essencialmente à correção de atos ou omissões que caracterizassem insubordinação dos órgãos hierarquicamente inferiores; com o tempo, foi adaptada a diferentes finalidades, mas suas principais características mantiveram-se associadas à afirmação da autoridade da decisão no caso em concreto em que proferidas.

No segundo capítulo serão analisadas algumas das principais hipóteses de cabimento da reclamação. Serão traçadas as especificidades de cada uma para compreender se e em que medida as hipóteses acrescidas pelo Código de Processo Civil decorrem daquelas anteriormente existentes, e quais as principais semelhanças e diferenças entre elas. $\mathrm{O}$ exame das hipóteses de cabimento permitirá delimitar os contornos da análise que será levada a cabo no capítulo IV.

A reclamação sempre foi vista como um instrumento célere por natureza. A possibilidade de cortar caminho aos tribunais superiores, a limitação da matéria a ser decidida, sua função exclusivamente rescindente e o requisito de prova pré-constituída permitiram que se atribuísse a esse remédio processual excepcional efetividade, o que parece 
ter sido relevante para o legislador de 2015 associá-lo aos precedentes obrigatórios. É necessário analisar em que medida a ampliação de suas hipóteses de cabimento e a sua ligação aos precedentes atende a essa expectativa.

A análise da reclamação como meio de controle da aplicação dos precedentes está estreitamente relacionada às ferramentas introduzidas pelo Código de Processo Civil de 2015 para a sua operacionalização. O terceiro capítulo será dedicado às principais características do sistema de precedentes, com foco na maneira como são utilizados como elemento de justificação de decisões judiciais e na forma de se verificar sua inobservância. Esses pontos permitirão traçar o conteúdo da impugnação de decisões judiciais em confronto com precedentes.

No quarto capítulo deste trabalho será analisada a forma como se dá, por meio da reclamação, a impugnação de uma decisão judicial que aplica ou deixa de aplicar um precedente. Também serão analisadas as principais consequências da atribuição dessa nova função à reclamação. Para tanto, examinar-se-á a possibilidade de a reclamação e o recurso serem manejados simultaneamente contra a mesma decisão judicial, com intuito de compreender se essa concorrência de meios de impugnação é justificável. Será possível verificar, assim, em que medida o controle da aplicação do precedente por meio de recurso difere da reclamação, principalmente no que diz respeito aos efeitos de cada instrumento.

Assim, serão lançadas as bases para o desenvolvimento de uma análise crítica da ampliação das hipóteses de cabimento da reclamação e do seu papel como instrumento de controle da aplicação de precedentes. 


\section{CONClusão}

Conforme já se adiantou, a análise desenvolvida neste trabalho permitiu concluir que conferir à reclamação a função de meio de controle da aplicação de precedentes não foi uma opção legislativa adequada.

Chegou-se a essa conclusão a partir duas linhas de raciocínio: (I) os recursos e os meios de impugnação previstos no ordenamento são adequados para promover a análise da inobservância do precedente, o que leva à conclusão de que os efeitos negativos da expansão das hipóteses de cabimento da reclamação, principalmente perante os tribunais de superposição, não são justificáveis; e (II) a reclamação não é instrumento compatível com um sistema de precedentes.

Demonstrou-se que os precedentes aos quais foi conferida força vinculante no Código de Processo Civil de 2015 prescindem da reclamação para assegurar sua observância, e que os demais meios de impugnação são perfeitamente aptos a atingir o mesmo resultado que a reclamação. A eficácia normativa conferida aos precedentes impõe que a tese jurídica neles identificada seja observada sempre que aplicável ao caso, o que independe do cabimento da reclamação. O cabimento da reclamação apenas adicionaria um meio pelo qual a decisão possa ser atacada.

A violação da norma do precedente se assemelha à violação da lei, e, quando a reclamação é fundada na inobservância de um precedente, sua função é muito semelhante àquela de um recurso. Uma vez que nessa hipótese a reclamação exerce função que poderia ser integralmente abrangida pelos recursos e demais meios de impugnação existentes, não há razão se admitir que a mesma decisão seja impugnada simultaneamente por reclamação e recurso.

A concorrência de meios de impugnação de decisões judiciais é excepcional no ordenamento. Observou-se que a concorrência entre a reclamação e o recurso como meios de impugnação sempre foi justificada pela diferente função exercida por esses remédios processuais. Entretanto, essa explicação apenas procede quando a reclamação exerce a função de assegurar a autoridade de uma decisão anteriormente proferida, situação em que a decisão é desconstituída sem que outra seja prolatada. Trata-se de entendimento que não leva em consideração as hipóteses em que a reclamação se volta contra a violação de um precedente. Nessas hipóteses, repete-se, a reclamação exerce função muito semelhante à de um recurso, de modo que a impugnação simultânea pelas duas vias não se justifica. 
Não parece haver dúvida de que o resultado que se procura obter com a reclamação pode ser integralmente alcançado pelos demais instrumentos previstos no ordenamento. Nessa medida, a ampliação das hipóteses de cabimento da reclamação pelo Código de Processo Civil vai, de certo modo, na contramão da tendência de reduzir os recursos e os seus efeitos, conforme enunciado na Exposição de Motivos do Anteprojeto.

Ainda que se admita que a reclamação é o meio mais eficaz, rápido e econômico para impor respeito aos precedentes, tudo indica que os malefícios decorrentes de sua larga utilização - sobretudo em paralelo aos recursos existentes no ordenamento - superariam os benefícios, levando-se em conta ainda a grave incoerência criada no sistema de impugnação das decisões judiciais.

Mas o argumento de que a reclamação seria um mecanismo célere para impor a observância dos precedentes também não procede. Ao passo que a impugnação da decisão por meio de recurso permite desde logo que a decisão seja reformada, pois os recursos são dotados de efeitos rescindente e substitutivo, a procedência da reclamação leva apenas à desconstituição da decisão judicial, sendo necessário o retorno ao órgão a quo para novo pronunciamento, o que é uma significativa desvantagem da reclamação com relação aos recursos e traz inconvenientes práticos.

Ademais, é inevitável concluir que, na sistemática implementada pelo Código de Processo Civil de 2015, a violação aos precedentes é repelida mais fortemente do que a violação à lei federal ou à própria Constituição Federal. A violação ao precedente pode ser atacada por dois mecanismos de impugnação simultâneos, sendo que um deles permite acessar diretamente os órgãos de cúpula do Poder Judiciário. O ultraje à lei e à Constituição, ainda que flagrantes, apenas podem ser impugnados pelos recursos, e a matéria somente será submetida aos tribunais de superposição quando preenchidos os rigorosos requisitos de admissibilidade dos recursos excepcionais, que não são aplicáveis à reclamação.

Não se pode confundir a relevância em assegurar a observância da interpretação conferida pelos tribunais de superposição às matérias que lhes compete julgar com o acesso imediato aos tribunais de superposição. Assim fosse, seria necessário que a violação da lei federal e de normas constitucionais também fosse dotada de um mecanismo de reforço que permitisse o acesso imediato ao Supremo Tribunal Federal e ao Superior Tribunal de Justiça.

A concepção de que a reclamação seria um mecanismo célere para fazer cessar desvios dos órgãos inferiores está intimamente relacionada à origem do instituto, com base 
na teoria dos poderes implícitos. Ele foi desenvolvido pela jurisprudência do Supremo Tribunal Federal para reafirmar a autoridade daquela corte sobre os demais órgãos do Poder Judiciário. Voltava-se à correção de atos ou omissões que caracterizassem insubordinação dos órgãos hierarquicamente inferiores e tinha caráter essencialmente disciplinar, confundindo-se com o seu principal antecedente histórico - a correição parcial. Dessa forma, cabia ao tribunal cuja autoridade havia sido desautorizada impor a conduta adequada ao órgão inferior, sem que fosse necessário verificar o erro ou acerto da decisão afrontosa. É nítido, portanto, o seu viés repressivo, que não é adequado a um sistema de precedentes. A reclamação é um instrumento mais adequado à imposição do decisum em um caso concreto do que ao debate da aplicação do precedente.

Desde sua origem a reclamação é mecanismo de reforço que, nas palavras de MARCELO DANTAS, "revela uma tibieza do nosso sistema judiciário processual constitucional" $^{\text {391 }}$ Observa-se que a concepção de que a reclamação é um mecanismo de reforço repercutiu na sua disciplina pelo Código de Processo Civil, uma vez que lhe foi atribuído o papel de assegurar a observância dos precedentes antevendo a dificuldade de se instaurar uma cultura de respeito a estes pronunciamentos, quando, na verdade, sua obrigatoriedade independe de mecanismo específico de impugnação.

Deve-se frisar que a forma de aplicação de precedentes não é mecânica; em nada se confunde com a imposição do preceito extraído de uma decisão, como se verifica na hipótese em que a reclamação visa a garantir a autoridade de uma decisão proferida no mesmo caso concreto. Trata-se de atividade hermenêutica, que demanda a identificação da ratio decidendi do precedente, a confrontação entre os casos e a verificação de distinções que justifiquem ou não a não-aplicação daquela tese jurídica ao caso concreto.

A associação entre a reclamação e determinados precedentes com força vinculante instituídos pelo Código de Processo Civil teve como intuito valorizar esses precedentes e inibir a sua infringência, associando-os a um instrumento especialmente enérgico e eficiente para tolher os efeitos da decisão exorbitante. Esse escopo teria sido melhor atingido caso esse instrumento tivesse sido dotado de efeito rescindente e substitutivo.

Admitindo-se que a reclamação deva ser compreendida como meio para se questionar a forma como determinado precedente foi interpretado e aplicado, e não de

\footnotetext{
${ }^{391}$ DANTAS, Reclamação Constitucional no Direito Brasileiro, p. 514.
} 
simples imposição de sua obrigatoriedade, não há razão para que a decisão judicial que viole um precedente possa ser impugnada simultaneamente por dois instrumentos. Tampouco há razão para a reclamação seja direcionada ao órgão cuja autoridade foi desrespeitada, que consiste em uma herança da origem correicional do instituto.

Como foi demonstrado, a concepção de que a correta interpretação do precedente deve ser necessariamente realizada pelo órgão que proferiu a decisão originalmente é absolutamente contrária à atividade interpretativa intrínseca à aplicação das razões determinantes do precedente vinculante. Trata-se de medida de viés autoritário que tenderia a restringir a participação dos tribunais inferiores no processo interpretativo, como se lhes coubesse apenas o papel de "boca do precedente".

Além de a reclamação não se mostrar instrumento adequado ou necessário para assegurar a observância dos precedentes vinculantes, ela promove significativo aumento no volume de trabalho principalmente dos tribunais de superposição; nessa medida, vai na contramão da busca por celeridade que norteou a reformulação de diversos institutos pela lei vigente, incluindo-se nessa categoria a própria reclamação.

Se antes mesmo da ampliação de suas hipóteses de cabimento o STF e o STJ já conferiam à reclamação tratamento restritivo, é provável que com a ampliação de suas hipóteses de cabimento sejam criados inúmeros óbices à sua admissibilidade, podendo cogitar-se da formação de uma "jurisprudência defensiva" destinada a obstaculizar o exame de mérito da reclamação. 


\section{BIBLIOGRAFIA}

ABBOUD, Georges. "Precedente judicial versus jurisprudência dotada de efeito vinculante." In: WAMBIER, Teresa Arruda Alvim (coord.). Direito jurisprudencial. São Paulo: RT, 2012.p. 491-552.

ANFE, Ariana Júlia de Almeida. Técnicas de utilização de precedentes - Estudo comparativo: Inglaterra - Estados Unidos - Brasil. Dissertação (Mestrado). São Paulo, Faculdade de Direito da Universidade de São Paulo, 2016.

ARRUDA ALVIM, José Manoel de. "Correição parcial." Revista dos Tribunais, São Paulo, v. 62 , n. 452 , jun. 1973, p. 11-20.

ARRUDA ALVIM, José Manoel de. "Súmula e súmula vinculante." In: MediNA, José Miguel Garcia; CruZ, Luana Pedrosa Figueiredo; CerqueIra, Luís Otávio Sequeira DE; GOMES JUNIOR, Luiz Manoel (Coord.) Os poderes do juiz e o controle das decisões judiciais. São Paulo: RT, 2008.

ARAÚJO, José Henrique Mouta. "Duração razoável do processo e a ampliação do cabimento da reclamação constitucional." In: NOGUEIRA, Pedro Henrique Pedrosa; COSTA, Eduardo José da Fonseca (Org.). Reclamação constitucional. Salvador: Juspodivm, 2013.

ARAÚJO, José Henrique Mouta. "A reclamação constitucional e os precedentes vinculantes: o controle da hierarquização interpretativa no âmbito local”. Revista de Processo, São Paulo, v. 41, n. 252, p. 243-262, fev. 2016.

ASSIS, Araken de. Manual dos recursos. 8. ed. São Paulo: RT, 2016.

ASSIS, Araken de. Introdução aos sucedâneos recursais. NERY JR., Nelson; WAMBER, Teresa Arruda Alvim (coords.). Aspectos polêmicos e atuais dos recursos e de outros meios de impugnação às decisões judiciais. São Paulo: RT, 2002, v. 6, p. 17ss. 
BARBOSA MOREIRA, José Carlos. Comentários ao Código de Processo Civil, v. V. Rio de Janeiro: Forense, 2011.

BARBOSA MOREIRA, José Carlos. "Súmula, jurisprudência, precedente: uma escalada e seus riscos.” Temas de direito processual - nona série. São Paulo: Saraiva, 2007.

BARBOSA MOREIRA, José Carlos. “A Emenda Constitucional n 45 e o processo”. Temas de Direito Processual, nona séria, São Paulo: Saraiva, 2007.

BARREIROS, Lorena Miranda. Estruturação de um sistema de precedentes no Brasil e concretização da igualdade: desafios no contexto de uma sociedade multicultural". In: DIDIER JR., Fredie; CUNHA, Leonardo Carneiro da; ATAÍDE JR., Jaldemiro Rodrigues de; MACÊDO, Lucas Buril de. (Coords.). Precedentes. Salvador: Juspodivm, 2015.

BUSTAMANTE, Thomas da Rosa. Teoria do precedente judicial, S. Paulo: Noeses, 2012.

CÂMARA, Alexandre Freitas. O novo processo civil brasileiro. $2^{\mathrm{a}}$ ed. São Paulo: Atlas, 2016.

CAMBI, Eduardo. “Súmulas vinculantes.” Revista de Processo, v. 168, p. 143, fev. 2009.

CALAMANDREI, Piero. La Cassazione civile, in Opere Giuridiche, v. VI, VII e VIII, Napoli, 1979.

CÔRTES, Osmar Mendes Paixão. "A reclamação no novo CPC - fim das limitações impostas pelo tribunal ao cabimento?” Revista de Processo, v. 244/2015, p. 347-358.

CÔRTES, Osmar Mendes Paixão. “A reclamação para os tribunais superiores no novo CPC, com as alterações da lei 13.256/2016" Revista de Processo, São Paulo, v. 257/2016, p. 255266, fev. 2016.

CRAMER. Ronaldo. Precedentes judiciais: teoria e dinâmica. Rio de Janeiro: Forense, 2016. 
CROSS, Rupert; HARRIS, J.W. Precedent in English law, Oxford, Clarendon Press, 1991.

CUNHA, Leonardo José Carneiro da. "Natureza jurídica da reclamação constitucional." In: NERY JUNIOR, Nelson; WAMBIER, Teresa Arruda Alvim. Aspectos polêmicos e atuais dos recursos cíveis e de outros meios de impugnação das decisões judiciais. v. 8. São Paulo: RT, 2005. p. 325-341.

DANTAS, Bruno; WAMBIER, Teresa Arruda Alvim. Recurso Especial, Recurso Extraordinário e a nova função dos tribunais superiores no direito brasileiro. $3^{\mathrm{a}}$ ed. São Paulo: Revista dos Tribunais, 2016.

DANTAS, Marcelo Navarro Ribeiro. Reclamação Constitucional no Direito Brasileiro. Porto Alegre: Sérgio Antonio Fabris, 2000.

DANTAS, Marcelo Navarro Ribeiro. “Correição parcial não é recurso (portanto, não deve utilizado como tal)". In: NERY JR., Nelson; WAMBIER, Teresa Arruda Alvim (Coord.). Aspectos polêmicos e atuais os recursos cíveis e outros meios de impugnação das decisões judiciais. v. 4. São Paulo: RT, 2011.

DANTAS, Marcelo Navarro Ribeiro. "Novidades em reclamação constitucional: seu uso para impor o cumprimento da súmula vinculante”. In: MEDINA, José Miguel Garcia; CRUZ, Luana Pedrosa Figueiredo; CERQUEIRA, Luís Otávio Sequeira de; GOMES JUNIOR, Luiz Manoel (Coord.) Os poderes do juiz e o controle das decisões judiciais. São Paulo: RT, 2008.

DAVID, René. Os grandes sistemas de direito contemporâneo. São Paulo: Martins Fontes, 2002.

DIDIER Jr. Fredie; BRAGA, Paula Sarno; OLIVEIRA, Rafael Alexandria de. Curso de direito processual civil: teoria da prova, direito probatório, ações probatórias, decisão, precedente, coisa julgada e antecipação dos efeitos da tutela. v. 2. Salvador: Juspodivm, $11^{\mathrm{a}}$ ed., 2016. 
DIDIER JR., Fredie; CUNHA, Leonardo Carneiro da. Curso de direito processual civil: meios de impugnação às decisões judiciais e processo nos tribunais. v. 3. Salvador: Juspodivm, 13a ed., 2016.

DIDIER JR., Fredie. "Sistema brasileiro e precedentes judiciais obrigatórios e os deveres institucionais dos tribunais: uniformidade, estabilidade, integridade e coerência da jurisprudência.” In: DIDIER JR., Fredie; CUNHA, Leonardo Carneiro da; ATAÍDE JR., Jaldemiro Rodrigues de; MACÊDO, Lucas Buril de. (Coords.). Precedentes. Salvador: Juspodivm, 2015.

DINAMARCO, Cândido Rangel. Nova era do processo civil. $4^{\mathrm{a}}$ ed. São Paulo: Malheiros, 2013.

DINAMARCO, Cândido Rangel. "O relator, a jurisprudência e os recursos". In: NERY JUNIOR, Nelson; WAMBIER, Teresa Arruda Alvim. Aspectos polêmicos e atuais dos recursos cíveis de acordo com a Lei 9.756/98. São Paulo: RT, 1999, p. 129.

DINAMARCO, Cândido Rangel. Fundamentos do processo civil moderno. $6^{\mathrm{a}}$ ed., v. I, São Paulo: Malheiros, 2010.

DINAMARCO, Cândido Rangel. "A função das cortes supremas na América Latina”, in Fundamentos do Processo Civil moderno, II, S. Paulo, Malheiros, 2010.

DINAMARCO, Cândido Rangel. Instituições de direito processual civil, I, $8^{\text {a }}$ ed., S. Paulo, Malheiros, 2016.

DINAMARCO, Cândido Rangel; LOPES, Bruno Vasconcelos Carrilho. Teoria geral do novo processo civil. 2 ed., São Paulo: Malheiros, 2017.

DUXBURY, Neil. The nature and authority of precedent. Cambridge: Cambridge University Press, 2008, p. 1.

FERREIRA, William Santos. "Súmula vinculante: solução concentrada: vantagens, riscos e a necessidade de um contraditório de natureza coletiva (amicus curiae)” In: WAMBIER, Teresa Arruda Alvim; WAMBIER, Luiz Rodrigues; FISCHER, Octávio Campos; 
FERREIRA, William Santos(coords.). Reforma do Judiciário: primeiras reflexões sobre a Emenda Constitucional n. 45/2004. São Paulo: RT, 2005.

FERNANDES, André Dias; LiMA, Tiago Asfor Rocha. "Reclamação e causas repetitivas: alguns pontos polêmicos.” In: DIDIER JR., Fredie; CUNHA, Leonardo Carneiro da. Julgamento de casos repetitivos. Salvador: Juspodivm, 2016.

GOES, Gisele Santos Fernandes. Reclamação constitucional. In: DIDIER JR., Fredie (org.).Ações constitucionais. Salvador: JusPodium, 2006.p. 501-522

GÓES, Gisele. “A reclamação constitucional”. In: WAMBIER, Teresa Arruda Alvim; NERY JR., Nelson. (Org.). Aspectos polêmicos e atuais dos recursos cíveis. v. 8. São Paulo: RT, 2005.

GIANNICO, Maurício. A preclusão no direito processual civil brasileiro. São Paulo: Saraiva, 2005.

GRINOVER, Ada Pellegrini. "Da reclamação," Revista Brasileira de Ciências Criminais. Vol. 38/2002, p. 75-83.

GRINOVER, Ada Pellegrini. “A reclamação para garantia da autoridade das decisões dos tribunais.” In: O processo: estudos e pareceres.2. ed. São Paulo: DPJ, 2005.

JACOB, Cesar Augusto Alckmin. A reclamação como instrumento de controle da aplicação de precedentes do STF e do STJ: análise funcional, estrutural e crítica. Dissertação (mestrado). São Paulo, Faculdade de Direito da Universidade de São Paulo, 2015.

JORGE, Flávio Cheim. Teoria geral dos recusos cíveis. 7ª ed. São Paulo: RT, 2015.

LEAL, Victor Nunes. Problemas de Direito Público e outros Problemas. Brasília: Ministério da Justiça, 1997.

LEONEL, Ricardo de Barros. Reclamação Constitucional. São Paulo: Revista dos Tribunais, 2011. 
LIMA, Alcides Mendonça. Introdução aos recursos cíveis, 2a ed., São Paulo, RT, 1976.

LIMA, Tiago Asfor Rocha; FERnANDES, André Dias. "Reclamação e causas repetitivas: alguns pontos polêmicos”. In: DIDIER JR., Fredie; CUNHA, Leonardo Carneiro da. Julgamento de casos repetitivos. Salvador: Juspodivm, 2016.

LOPES, Bruno Vasconcelos Carrilho. "Súmula vinculante”. In: GIANNICO, Maurício; MONTEIRO, Vítor José de Mello (Org.). As novas reformas do CPC e de outras normas processuais. São Paulo: Saraiva, 2008.

LOPES FILHO, Juraci Mourão. Os precedentes judiciais no constitucionalismo brasileiro contemporâneo. Salvador: Juspodivm, 2016.

LUCCA, Rodrigo Ramina de. O dever de motivação das decisões judiciais. Salvador: Juspodivm, 2015.

LUCON, Paulo Henrique dos Santos. "Evolução da Reclamação Constitucional e seu emprego para assegurar a autoridade dos precedentes”. In: CRUZ E TUCCI, José Rogério; RODRIGUES, Walter Piva; AMADEO, Rodolfo da Manso Real. Processo civil: homenagem a José Ignácio Botelho de Mesquita. São Paulo: Quartier Latin, 2013.

MACÊDO, Lucas Buril de. "Reclamação Constitucional fundada em precedentes obrigatórios no CPC/2015". Novo CPC doutrina selecionada, v. 6: processo nos Tribunais e Meios de Impugnação às decisões judiciais. Salvador: Juspodivm, 2015.

MACÊDO, Lucas Buril de. Precedentes judiciais e o direito processual civil. Salvador: Juspodivm, 2016.

MACÊDO, Lucas Buril de. “O regime jurídico dos precedentes judiciais no projeto do novo código de processo civil.” Revista de Processo, São Paulo, v. 237, nov. 2014, p. 369-401.

MACÊDO, Lucas Buril de. "Contributo para a definição de ratio decidendi na teoria brasileira dos precedentes judiciais." In: DIDIER JR., Fredie; CUNHA, Leonardo Carneiro da; ATAIIDE JR., Jaldemiro Rodrigues de; MACÊDO, Lucas Buril de. (Coords.). Precedentes. Salvador: Juspodivm, 2015. 
MANCUSO, Rodolfo de Camargo. Sistema brasileiro de precedentes. São Paulo: RT, 2016.

MARCATO, Antonio Carlos. Crise da Justiça e influência dos precedentes judiciais no direito processual civil brasileiro. Tese (Professor Titular) - Faculdade de Direito da Universidade de São Paulo, São Paulo, 2009.

MARINONI, Luiz Guilherme. Precedentes Obrigatórios. $4^{\mathrm{a}}$ ed. São Paulo: Revista dos Tribunais, 2016.

MARINONI, Luiz Guilherme. O STJ enquanto corte de precedentes. São Paulo: Revista dos Tribunais, 2013.

MARINONI, Luiz Guilherme. Julgamento nas Cortes Supremas: precedentes e decisão do recurso diante do novo CPC. $1^{\text {a }}$ ed. São Paulo: Revista dos Tribunais, 2016.

MARINONI, Luiz Guilherme. A ética dos precedentes. São Paulo: RT, 2014.

MARTINS, Ives Gandra da Silva; PAVAN, Cláudia Fonseca Morato. Reclamação constitucional e ação declaratória de constitucionalidade. Nogueira, Pedro Henrique Pedrosa; Costa, Eduardo José da Fonseca (org.). Reclamação constitucional. Salvador: Juspodivm, 2013.

MELlO, Patrícia Perrone Campos. Precedentes - O desenvolvimento judicial do direito no constitucionalismo contemporâneo. Rio de Janeiro: Renovar, 2008.

MELLO, Patricia Perrone Campos. O Supremo Tribunal Federal e os precedentes vinculantes. In: JAYME, Fernando Gonzaga; Mendes, Aluísio e Nunes, Dierle (coords.). A nova aplicação da jurisprudência e precedentes no CPC/2015 - estudos em homenagem à professora Teresa Arruda Alvim. São Paulo: RT, 2017.

MITIDIERO, Daniel. "Precedentes, jurisprudência e súmulas no novo Código de Processo Civil”. Revista de Processo, vol. 245/2015, p. 333-349.

MITIDIERO, Daniel. Precedentes: da persuasão à vinculação. São Paulo: Revista dos Tribunais, 2016. 
MITIDIERO, Daniel. Cortes Superiores e Cortes Supremas: do controle à interpretação, da jurisprudência ao precedente. São Paulo: RT, 2013.

MONIZ DE ARAGÃO, Egas Dirceu. A correição parcial. São Paulo: José Bushatsky, 1969

MORATO, Leonardo Lins. Reclamação e sua aplicação para o respeito da súmula vinculante. São Paulo: Revista dos Tribunais, 2007.

MOTTA, Otávio Verdi. Justificação da decisão judicial: a elaboração da motivação e a formação do precedente. São Paulo: RT, 2015, p. 151.

MOUZALAS, Rinaldo; ALBUQUERQUE, João Otávio Terceiro Neto Bernardo de. “Reclamação Constitucional” In: DIDIER Jr., Fredie; CunHA, Leonardo Carneiro da; ATAÍDE JR., Jaldemiro Rodrigues de; MACÊDO, Lucas Buril de. (Coords.). Precedentes. Salvador: Juspodivm, 2015.

NEVES, Daniel Amorim Assumpção. Manual de Direito Processual Civil. $8^{\mathrm{a}}$ ed. Salvador: Juspodivm, 2016.

NEVES, Daniel Amorim Assumpção. Ações constitucionais. Salvador: Juspodivm, 3 ed., 2017.

NERY JUNIOR, Nelson. Teoria geral dos recursos. São Paulo: RT, 2014.

NERY JUNIOR, Nelson; ABBOUD, Georges. Stare decisis vs. direito jurisprudencial. In: FREIRE, Alexandre; DANTAS, Bruno; NUNES, Dierle; DIDIER JR., Fredie; MEDINA, José Miguel Garcia; FUX, Luiz; CAMARGO, Luiz Henrique Volpe; OLIVEIRA, Pedro Miranda de (org.). Novas tendências do processo civil - Estudos sobre o projeto do novo Código de Processo Civil. Salvador: JusPodivm, 2013. p. 491.

NERY JUNIOR, Nelson; ABBOUD, Georges. "Recursos para os tribunais superiores e a lei 13.256/2016". Revista de processo. São Paulo, v. 257, jul. 2016, p. 217-235. 
NUNES, Dierle. “Aplicação de precedentes e 'distinguishing' no CPC/2015: uma breve introdução.” In: DIDIER Jr., Fredie; CunHA, Leonardo Carneiro da; ATAÍDE JR., Jaldemiro Rodrigues de; MACÊDO, Lucas Buril de. (Coords.). Precedentes. Salvador: Juspodivm, 2015.

OLIVEIRA, Pedro Miranda de. “Aspectos destacados da reclamação no novo código de processo civil.” Revista de Processo, vol. 247/2015, p. 299-318.

PACHECO, José da Silva. "A 'reclamação' no STF e no STJ de acordo com a nova Constituição". Revista dos Tribunais, v. 646, p. 19.

PEIXOTO, Ravi. Superação do precedente e segurança jurídica. Salvador: Juspodivm, 2015.

PEIXOTO, Ravi. "Proibição da venda casada de reclamação e precedentes obrigatórios." Disponível em http://justificando.com/2015/04/23/proibicao-da-venda-casada-dereclamacao-e-precedentes-obrigatorios/. Consultado em 20 de dezembro de 2016.

RE, Edward D. Stare Decisis. Revista dos Tribunais, vol. 702/1994, p. 7-13

RODRIGUES, Marco Antonio. Manual dos Recursos, ação rescisória e reclamação. São Paulo: Atlas, 2017.

RUSCIANO, Silvia. Nomofilachia e ricorso in Cassazione, Torino, G. Giappichelli, 2012.

SALLES, José Carlos de Moraes. Súmula vinculante: solução ou retrocesso? Revista dos Tribunais, v. 864, p. 11, out. 2007.

SCHAUER, Frederick. Thinking like a lawyer. Cambridge: Harvard University Press, 2009.

SICA, Heitor Vitor Mendonça. "Congestionamento viário e congestionamento judiciário". Revista de Processo, São Paulo, v. 236/2014, out./2014, p. 13-26.

SILVA, Ovídio A. Baptista da. "A função dos Tribunais Superiores". Sentença e coisa julgada. 4. ed. Rio de Janeiro: Forense, 2006. p. 299. 
SILVA, Narda Roberta da. -- A eficácia dos precedentes no novo CPC. Uma reflexão à luz da teoria de Michele Taruffo. Revista de Processo. São Paulo. v.39. n.228. p.343-55

STRECK, Lenio Luiz; ABBOUD, Georges. O que é isso? O precedente judicial e as súmulas vinculantes? Porto Alegre: Livraria do Advogado, 3ed., 2015.

STRECK, Lenio Luiz; ABBOUD, Georges. "O NCPC e os precedentes - afinal, do que estamos falando?" Coleção grandes temas do novo CPC: v. 3 - Precedentes. Salvador: Juspodivm, 2015.

TALAMINI, Eduardo. Novos aspectos da jurisdição constitucional brasileira: repercussão geral, força vinculante, modulação dos efeitos do controle de constitucionalidade e alargamento do objeto do controle difuso. Tese (Livre docência). São Paulo, Faculdade de Direito da Universidade de São Paulo, 2008.

TALAMINI, Eduardo. Objetivação do controle incidental de constitucionalidade e força vinculante (ou "devagar com o andor que o santo é de barro"). In: NERY JUNIOR, Nelson;WAMBIER, Teresa Arruda Alvim. Aspectos polêmicos e atuais dos recursos cíveis e assuntos afins.São Paulo: RT, 2011.v. 12.

TALAMINI, Eduardo. O que são os 'precedentes vinculantes' no CPC/15. Disponível em http://www.migalhas.com.br/dePeso/16,MI236392,31047-

O+que+sao+os+precedentes+vinculantes+no+CPC15> (consultado em $1^{\circ}$ de junho de 2016).

TARUFFO, Michele. Il vertice ambíguo - saggi sulla cassazione civile, Bologna, Il Mulino, 1991.

TARUFFO, Michele. Precedente e jurisprudência. Revista de Processo, v. 199, Set/2011, p. $139-155$.

THEODORO JÚNIOR, Humberto. Curso de Direito Processual Civil, vol. 3, 48 a ed. Rio de Janeiro: Forense, 2016.

TUCCI, José Rogério Cruz e. Precedente judicial como fonte do Direito. São Paulo: RT, 2004. 
TUCCI, José Rogério Cruz e. "O regime do precedente judicial no novo CPC." Coleção grandes temas do novo CPC: v. 3 - Precedentes. Salvador: Juspodivm, 2015, p. 445-457.

TUCCI, José Rogério Cruz e. "Parâmetros de eficácia e critérios de interpretação do precedente judicial”. In: WAMBIER, Teresa Arruda Alvim (coord.). Direito jurisprudencial. São Paulo: Revista dos Tribunais, 2012.

TUCCI, José Rogério Cruz e. Comentários ao Código de Processo Civil - vol. 4 - arts. 926 a 1.072. In: BuENO, Cassio Scarpinella (coord.). São Paulo: Saraiva, 2017.

VEIGA, Daniel Brajal. O caráter pedagógico da reclamação constitucional e a valorização do precedente. Revista de processo, v. 220/2013, p. 49 - 67 , jun. / 2013.

WAMBIER, Luiz Rodrigues; TALAMINI, Eduardo. Curso avançado de processo civil: cognição jurisdicional (processo comum de conhecimento e tutela provisória). São Paulo: RT, 16 ed., 2016.

WAMBIER, Teresa Arruda Alvim. "Precedentes e evolução do direito", in WAMBIER, Teresa Arruda Alvim (coord.), Direito Jurisprudencial, S. Paulo, RT, 2012.

WAMBIER, Teresa Arruda Alvim. "Em direção ao common law?” In: MENDES, Aluisio Gonçalves de Castro; WAMBIER, Teresa Arruda Alvim (org.). O processo em perspectiva: Jornadas Brasileiras de Direito Processual. São Paulo: RT, 2013.p. 371-378.

WAMBIER, Teresa Arruda Alvim. “A vinculatividade dos precedentes e o ativismo judicial - paradoxo apenas aparente.” In: DIDIER Jr., Fredie; CUNHA, Leonardo Carneiro da; ATAÍDE JR., Jaldemiro Rodrigues de; MACÊDO, Lucas Buril de. (Coords.). Precedentes. Salvador: Juspodivm, 2015.

XAVIER, Carlos Eduardo Rangel. Reclamação constitucional e precedentes judiciais. São Paulo: Revista dos Tribunais, 2016.

ZANETI Jr., Hermes. O valor vinculante dos precedentes. $2^{a}$ ed. Salvador: Juspdivm, 2016. 
ZANETI JR., Hermes. "Precedentes normativos formalmente vinculantes.” In: DIDIER Jr., Fredie; CunHa, Leonardo Carneiro da; ATAÍDE JR., Jaldemiro Rodrigues de; MACÊDO, Lucas Buril de. (Coords.). Precedentes. Salvador: Juspodivm, 2015, p. 423.

ZUFELATO, Camilo. Precedentes judiciais vinculantes à brasileira no novo CPC: aspectos gerais. O novo Código de Processo Civil: questões controvertidas. São Paulo: Atlas, 2015. 